\title{
Prevalence of Near-Death Experiences in Australia
}

\author{
Mahendra Perera, M.B.B.S., Ph.D., M.D., \\ MRCPsych, FRANZCP \\ Albert Road Clinic, Melbourne, Australia \\ Gayan Padmasekara \\ Monash University, Clayton, Australia \\ John Belanti, B.S.W. \\ Broadmeadows Adult Mental Health \\ Broadmeadows, Australia
}

ABSTRACT: In the literature surveyed we found only two articles that dealt with the prevalence of near death experiences (NDEs) in a general population. The first study, from the United States, reported NDEs in 15 percent of the population. In a more strictly controlled study from Germany, the rate was 4 percent. The present study was performed to ascertain the prevalence of NDEs in Australia. We developed a questionnaire and administered it by telephone interview. We present that questionnaire here for further studies. We determined that 8 percent of the population reported an NDE. There was a 36 percent prevalence of people who had faced a situation of imminent death, almost one-fourth of whom reported an NDE.

KEY WORDS: near-death experience; prevalence; Australia; population study; questionnaire.

Mahendra Perera, M.B.B.S., Ph.D., M.D., MRCPsych, FRANZCP, is Consultant Psychiatrist at the Albert Road Clinic in Melbourne, Australia. Gayan Padmasekara is a medical student at Monash University in Clayton, Australia. John Belanti, B.S.W., is a mental health social worker at Broadmeadows Adult Mental Health in Broadmeadows, Australia. Reprint requests should be addressed to Dr. Perera at the Albert Road Clinic, 31 Albert Road, Melbourne VIC 3004, Australia; e-mail: mhp@ausdoctors.net. 
The prevalence of near-death experiences (NDEs) has been studied in various groups of people. These studies have been comprehensively reviewed by Bruce Greyson (1998), who concluded that NDEs occurred in 9 to 18 percent of the cohorts of patients who had come close to death.

There have been only a few studies exploring the prevalence of NDEs among the general public, as opposed to among people who had come close to death. One such survey was that conducted by the Gallup Poll organization in 1980-1981, in which they surveyed a representative sample of the American population (Gallup and Proctor, 1982). This was perhaps the first study of its kind. There was one question pertaining to NDEs, and it was part of a much larger study. They found that 15 percent of the population answered affirmatively to the question: "Have you, yourself, ever been on the verge of death or had a 'close call' which involved any unusual experience at that time?" (Gallup and Proctor, 1982, p. 200). Keith Basterfield (1988) attempted a questionnaire survey of NDE in Australia, but unfortunately the sample was neither random nor representative of the population. In a more limited survey in India, Satwant Pasricha noted that the prevalence of NDEs was 0.1 percent (Pasricha, 1995). A broader study conducted in Germany found that 4 percent of the sample reported having had an NDE (Knoblauch, Schmied, and Schnettler, 2001). More recently Jeffrey Long and Jody Long (2003) performed an Internet survey of NDE, but their objective was to find out if there were any differences in NDEs that occurred before and after the publication of Raymond Moody's work (1975), rather than to assess the prevalence of NDEs.

Except for the questions used in the Gallup Poll, which have been published, the other researchers have not published the questionnaires used in their studies. We were able to locate only three national surveys, and Pasricha's study from India was limited to certain areas. Hence, there were only two studies that had selected a nationally representative sample. The Gallup Poll had only one question, and it was a part of a wider exploration of views of the afterlife.

We therefore decided to study a nationally representative sample of the Australian populace with a view to being able to ascertain the prevalence of NDEs. Our second objective was to develop a readily administrable questionnaire and make it available for use in further research. 


\section{Methodology}

This prevalence study was performed by Roy Morgan Research (www.roymorgan.com), Australia's longest-established public opinion polling company, through the Roy Morgan CATIBUS (Computer Aided Telephone Interviewing System) Survey, which has a sampling variation at the national level of 1.3 percent to 2.9 percent. It was conducted in July 2004 on a nationally representative sample of 673 interviews drawn from a parent population of $16,277,000$. The respondents were contacted through a telephone survey. The population was selected through stratified random sampling from the White Pages (www.whitepages.com.au) telephone listings. If a respondent refused to answer, then the interviewers attempted to locate another respondent with the same parameters that were used in choosing the first respondent. The minimum age of respondents was 14 years. Questions regarding near-death experiences were derived from the NDE Scale (Greyson, 1983) and a review of the relevant literature. We selected items that seemed to occur with a relatively high frequency and adapted them to the telephone interview format. The questions pertaining to the NDE aspects of the survey are found in the Appendix.

The NDE survey included two separate questioning modalities: one question (NDQ3) solicited unprompted responses and a follow-up question (NDQ4) prompted responses from a predetermined list of NDE elements, as specified in the Appendix. The original questionnaire that was submitted to the polling organization included the same list of NDE elements as possible responses to the prompted and unprompted questions (Appendix). However, the unprompted question (NDQ3) elicited responses suggesting extra elements that we had not included in the prompted follow-up question in the original questionnaire. Since these responses were not obtained until after the survey was completed, they were not available to the interviewers to add as possible responses to the prompted question at the time of the survey.

These "extra" elements that we had not anticipated and which were provided by respondents to the unprompted question (NDQ3) were provided to us word for word by the polling organization. After careful perusal, we disregarded comments that appeared unrelated to an NDE, such as "had a crushing pain in my chest" or "heard my mother calling from the other room." However, we included comments such as "hovered over my body" that appeared to link strongly with the 


\section{Table 1}

Total Number of NDE Items Endorsed

by Respondents

\begin{tabular}{cccc}
\hline & & $\begin{array}{c}\text { Percent of Those } \\
\text { Close to Dying } \\
\text { Items } \\
\text { Endorsed Respondents }\end{array}$ & $\begin{array}{c}\text { Percent of } \\
\text { Total Sample } \\
(n=64)\end{array}$ \\
\hline 6 & 2 & $0.8 \%$ & $0.3 \%$ \\
5 & 3 & $1.2 \%$ & $0.5 \%$ \\
4 & 5 & $2.0 \%$ & $0.7 \%$ \\
3 & 19 & $7.8 \%$ & $2.8 \%$ \\
2 & 31 & $12.9 \%$ & $4.6 \%$ \\
1 & 54 & $22.4 \%$ & $8.0 \%$ \\
\hline
\end{tabular}

elements of the NDE. These comments were counted as, and added to, the appropriate NDE elements that closely resembled their content.

In addition to the NDE questions, the following information was obtained from all of the respondents: age, sex, state in which they lived, educational level, marital status, employment status, occupation, and income status.

\section{Results}

Thirty-six percent $(n=241)$ of those questioned answered "yes" when asked: "At any time in your life have you ever felt that you were close to the point of dying?" We defined a near-death experience as having endorsed 2 or more near-death experience elements. We found that 47 percent $(n=114)$ of the participants who had come close to dying endorsed at least one NDE item, and 25 percent $(n=60)$ met our NDE criterion of endorsing at least 2 elements. Those 60 respondents whom we judged to have had NDEs comprised 9 percent of the total sample. We judged the strength of the NDE by the number of items endorsed; that is, the more items endorsed, the stronger the NDE. The numbers and percents of respondents who endorsed differing numbers of NDE items are presented in Table 1.

Feelings of peace and an out-of-body experience had the highest endorsement rates any elements. These data on frequency of various NDE elements, presented in Table 2, were derived from the responses 
Table 2

Frequency of Endorsement of Individual NDE Elements

\begin{tabular}{lccc}
\hline & Respondents & $\begin{array}{c}\text { Percent of Those } \\
\text { Close to Dying } \\
(n=241)\end{array}$ & $\begin{array}{c}\text { Percent of } \\
\text { Total Sample } \\
(n=673)\end{array}$ \\
\hline Feeling of peace & 61 & $25.3 \%$ & $9.1 \%$ \\
Out-of-body experience & 54 & $22.4 \%$ & $8.0 \%$ \\
Heard noises & 31 & $12.9 \%$ & $4.6 \%$ \\
Saw a light & 21 & $8.7 \%$ & $3.1 \%$ \\
Saw a tunnel & 16 & $6.6 \%$ & $2.4 \%$ \\
Saw deceased spirits & 16 & $6.6 \%$ & $2.4 \%$ \\
Going to unearthly place & 12 & $5.0 \%$ & $1.8 \%$ \\
Saw religious figures & 8 & $3.3 \%$ & $1.2 \%$ \\
Saw visions or images* & 8 & $3.3 \%$ & $1.2 \%$ \\
Altered perception of time* & 5 & $2.0 \%$ & $0.7 \%$ \\
Life flashed before my eyes* & 4 & $1.7 \%$ & $0.6 \%$ \\
Heard music or voices* & 3 & $1.2 \%$ & $0.4 \%$ \\
Saw my family's future* & 2 & $0.8 \%$ & $0.3 \%$ \\
\hline
\end{tabular}

* These responses were not prompted in section NDQ4 of the questionnaire, but were obtained only from respondents' comments in the "other" category in NDQ3. All other responses were summed responses from prompted (NDQ4) and unprompted (NDQ3) sections of the questionnaire.

of all survey participants, including those who reported only one element and hence were classed as not having had a NDE. More than half of those who were close to dying ( $n=127,53$ percent) did not report any NDE elements. Prompting in the follow-up question (NDQ4) elicited more endorsements of the NDE items than were obtained with the unprompted question (NDQ3).

\section{Discussion}

Even though the sample was drawn to be representative of the adult population, the survey was based on telephone interviews. Hence certain groups of people were not represented in this survey, such as those who do not have a telephone or whose telephone numbers were unlisted. Furthermore the interviewers used English as their medium of communication. Hence respondents who did not speak English were excluded. Special groups of people such as those in a residential care 
setting may not have been represented. It is also possible that the veracity of some responses is questionable. However, it is reassuring to note that the frequency of the NDE components was in keeping with the results obtained from other surveys of a similar nature. The relatively high endorsement of hearing noises may have been due to participants reporting actual physical events that were taking place around the respondent at the time of the NDE rather than just noises in the NDE.

We classified an NDE as a positive response to more than one element. For those readers who prefer a more stringent criterion for NDEs, we have provided in Table 1 the numbers of participants who endorsed increasing numbers of NDE elements. We chose to require more than one element order to eliminate the possibility that some persons may give one positive response merely by chance. It may be that some of the items in Table 2 such as "saw deceased spirits," "saw religious figures," and "saw visions or images" may refer to a common item. Further statistical analysis will be required to make this judgment. It is of interest to note that the life review, altered perception of time, and even vision of the future were reported. Craig Lundahl (2001) had commented on the occurrence of prophetic revelations as a feature of NDEs. We will present further analysis of the data sets in a later paper.

The NDE elements prompted for in the follow-up question (NDQ4) were predetermined. Examining the results, it is apparent that the prompts increased the endorsement rate of NDE items. It may be that this is an artifact of participants responding to interviewers' suggestions or it may be a genuine assistance to recollection. Further research will be required to elucidate this aspect. We recommend that NDE elements first be solicited without prompting, and then prompts may be used subsequently. Perhaps there ought to be a greater number of items that are prompted.

One of the sources of difficulty was that it was unclear whether responses to the items regarding fear and panic were in response to what was happening in a physical sense or whether they were referring to a fearful NDE. Rense Lange, Greyson, and James Houran (2004) had commented on the fact that true NDEs focus more on the esoteric aspect rather than on the standard response to stress.

Our view is that these figures are an approximation of the prevalence of NDEs in the Australian population, which we find to be similar to that of other countries. Our findings lend confirmation to the universality of NDEs. In addition to further studies of NDE in general populations in different parts of the world, it will be useful to focus on 
the occurrence of the NDE in those faced with near-death situations. Clinicians when dealing with people faced with such situations need to be mindful of the possibility of these individuals having had a NDE.

\section{References}

Basterfield, K. (1988). Australian questionnaire study of NDEs [Letter]. Journal of Near-Death Studies, 6, 199-201.

Gallup, G., and Proctor, W. (1982). Adventures in immortality: A look beyond the threshold of death. New York, NY: McGraw-Hill.

Greyson, B. (1983). The Near-Death Experience Scale: Construction, reliability, and validity. Journal of Nervous and Mental Diseases, 171, 369-375.

Greyson, B. (1998). The incidence of near-death experiences. Medicine and Psychiatry, 1, 92-99.

Knoblauch, H., Schmied, I., and Schnettler, B. (2001). Different kinds of near-death experience: A report on a survey of near-death experiences in Germany. Journal of Near-Death Studies, 20, 15-29.

Lange, R., Greyson, B., and Houran, J. (2004). A Rasch scaling validation of a 'core' neardeath experience. British Journal of Psychology, 95, 161-177.

Long, J., and Long, J. (2003). A comparison of near-death experiences occurring before and after 1975: Results from an Internet survey. Journal of Near-Death Studies, 22, 21-32.

Lundahl, C. R. (2001). Prophetic revelations in near-death experiences. Journal of NearDeath Studies, 19, 233-239.

Moody, R. A. (1975). Life after life. Covington, GA: Mockingbird Books.

Pasricha, S. (1995). Near-death experiences in South India: A systematic survey. Journal of Scientific Exploration, 9, 79-88.

\section{Appendix: NDE Questionnaire}

NDQ1. At any time in your life have you ever felt that you were close to the point of dying?

yes

no

can't say

If ever been close to dying, ask:

NDQ2. Can you briefly describe the situation that you were in when this happened? If necessary prompt: What situation where you in when you had this near death experience?

cardiac arrest/heart attack

motor accident

suicide attempt

critical illness

coma 


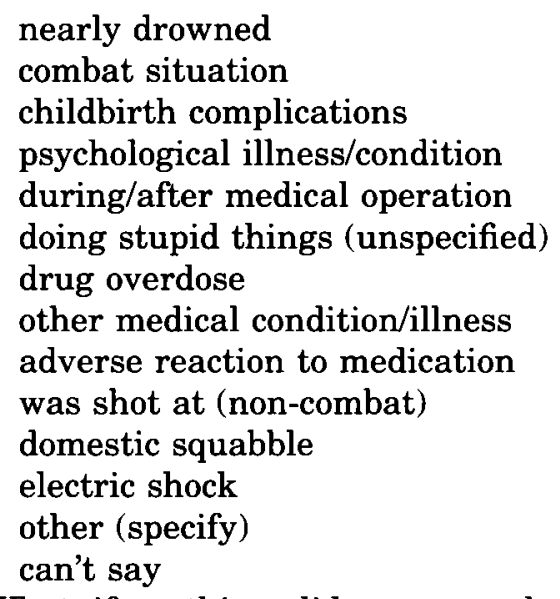

NDQ3. What, if anything, did you see or hear or feel during this near death experience? What else? Anything else? (Do not prompt but highlight any mentioned.)

out-of-body experience/felt as though outside my body saw a light

saw a tunnel

saw deceased spirits/people who had died

saw religious figures/Gods/angels

felt I was going to heaven/hell/purgatory/other unearthly place

had a feeling of peace

heard noises (pleasant/unpleasant)

other (specify)

can't say

nothing

NDQ4. In that near death situation did any of the following things happen? (Prompt by reading out and highlight all mentioned.)

Did you feel that you were outside your body?

Did you see a light?

Did you see a tunnel?

Did you see spirits of people who had died?

Did you see gods, angels, or other religious figures?

Did you feel you were in unearthly places, for example, heaven, hell, purgatory?

Did you have a feeling of peace?

Did you hear either pleasant or unpleasant noises?

None of the above? 